\title{
GESTÃO COSTEIRA PARA A CONSERVAÇÃO DOS RECURSOS NATURAIS DO MUNICIPIO DE CEDRAL, ESTADO DO MARANHÃO, BRASIL
}

\author{
Filipe Salomão de Sousa Ferreira ${ }^{(a)}$, Larissa Marques Rodrigues ${ }^{(b)}$, Marco Aurélio Neri Torres $^{(\mathrm{c})}$, \\ Antonio Cordeiro Feitosa ${ }^{(\mathrm{d})}$ \\ (a)Departamento de Geociências, Universidade Federal do Maranhão, salomão.filipe2@ gmail.com \\ (b) Departamento de Geociências, Universidade Federal do Maranhão, marco.torres.geo@ gmail.com \\ ${ }^{(c)}$ Departamento de Geociências, Universidade Federal do Maranhão,laroma1494@ gmail.com \\ (d)Departamento de Geociências, Universidade Federal do Maranhão, acfeitos@ gmail.com
}

\section{Eixo: DINÂMICA E GESTÃO DAS ZONAS COSTEIRAS}

\begin{abstract}
Resumo
As zonas costeiras são espaços preferenciais para as atividades humanas em face de suas potencialiddes como provedoras de recursos e o Município de Cedral, situado na extremidade ocidental do Golfâo Maranhense, possui uma zona costeira de extrema importância para a conservação da biodiversidade do Estado. O estudo analiza os instrumentos da gestão costeira de Cedral, inserida na APA das Reentrâncias Maranhenses, a pesquisa foi desenvolvida com base no método: dedutivo e indutivo, com os procedimentos metodológicos: levantamento e análise da bibliografia, entrevista com gestores, atividades de campo e registro fotográfico. Constata-se a reduzida intervenção de atores ambientais e de políticas públicas visando o fortalecimento da Gestão Costeira, fato que justifica a emergência de ações efetivas, pois atualmente só ocorrem ações isoladas e esporádicas que inviabilizam o cumprimento da legislação ambiental.
\end{abstract}

Palavras chaves: Gerenciamento Costeiro. Reentrâncias Maranhenses. Município de Cedral MA

\section{Introduçao}

As zonas costeiras são espaços preferenciais para as atividades humanas em face de suas potencialiddes como provedoras de recursos para a sobrebivência, suporte de meios e matérias primas para as práticas culturais mais diversas, além da posição estratégica que ocupam no âmbito dos processos de comunicação, circulação de bens e defesa do território, cujas características favorecem a ocorrência de vulnerabilidades que motivam a emergência de ações com propósito de preservação.

O Governo Brasileiro tem dispensado atenção continuada às zonas costeiras, fato que na atualidade, tem o propósito de atribuir para um uso mais sustentável dos seus ecossistemas, o que é evidenciado no compromisso governamental com o planejamento integrado da utilização de tais espaços visando o ordenamento da ocupação. No âmbito das ações governamentais, foi elaborado o Plano Nacional de Gerenciamento Costeiro (BRASIL, 1988; 2014). 
A costa maranhense possui grande importância no cenário brasileiro, estendendo-se no sentido oeste-leste por $640 \mathrm{~km}$, desde a foz do rio Gurupi à do rio Parnaíba (BRASIL, 2014) possuindo singularidades geoambientais expressas pelas maiores amplitudes de marés do país, inúmeras praias, ilhas, baías, enseadas, restingas, dunas, paleodunas e extensos manguezais, que justificam sua divisão em unidades de conservação federais como o Parque Nacional dos Lençóis Maranhenses e a APA do Delta do Parnaíba, e estaduais como as APA's da Baixada Maranhense e das Reentrâncias Maranhenses, além de suporte para muitos empreendimentos industriais e portuários.

O Município de Cedral, situado na extremidade ocidental do Golfâo Maranhense e inserido na APA das Reentrâncias Maranhenses, possui uma zona costeira de extrema importância para a conservação da biodiversidade do Estado.

O presente estudo tem como objetivo analisar os instrumentos de gestão da zona costeira do Município de Cedral, através da sistematização das informações e das ações ambientais desenvolvidas na área, identificação das principais unidades ambietais costeiras e litorâneas e avaliação do atual cenário ambiental, podendo subsidiar as ações futuras com vistas ao conhecimento do território e à políticas públicas compatíveis aos três de governos.

\section{Metodologia}

A pesquisa está pautada e fundamentada no método: dedutivo e indutivo. O método dedutivo subsidiou a pesquisa de gabinete, enquanto o indutivo foi utilizado como base na observação das modificações espaciais da área de estudo, considerando a observação dos fenômenos locais (KAPLAN, 1975).

Para efetivação da pesquisa foram utilizados os seguintes procedimentos metodológicos: levantamento e análise bibliográfica; levantamento da base cartográfica do município em formata de malha digital em sites específicos tais como o IBGE e o Ministério do Meio Ambiente; pesquisa de campo realizada entre os dias 19 a 22 de fevereiro de 2017 na área de pesquisa; entrevistas a funcionários da Prefeitura de Cedral e da secretaria de meio ambiente da mesma, do Instituto Brasileiro do Meio Ambiente e dos Recursos Naturais Renováveis (IBAMA) e da Secretaria Estadual de Meio Ambiente (SEMA) do Estado do Maranhão.

\section{Localização e caracterização ambiental da área de estudo.}

Inserido na extremidade oriental da APA das Reentrâncias, o município de Cedral - MA está localizado na borda ocidental do Golfão Maranhense (Figura 1) sendo delimitado pelos paralelos de 1'57'05" e

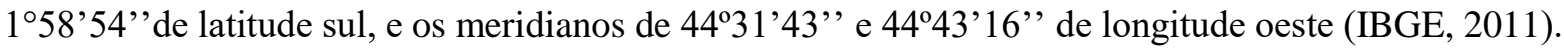




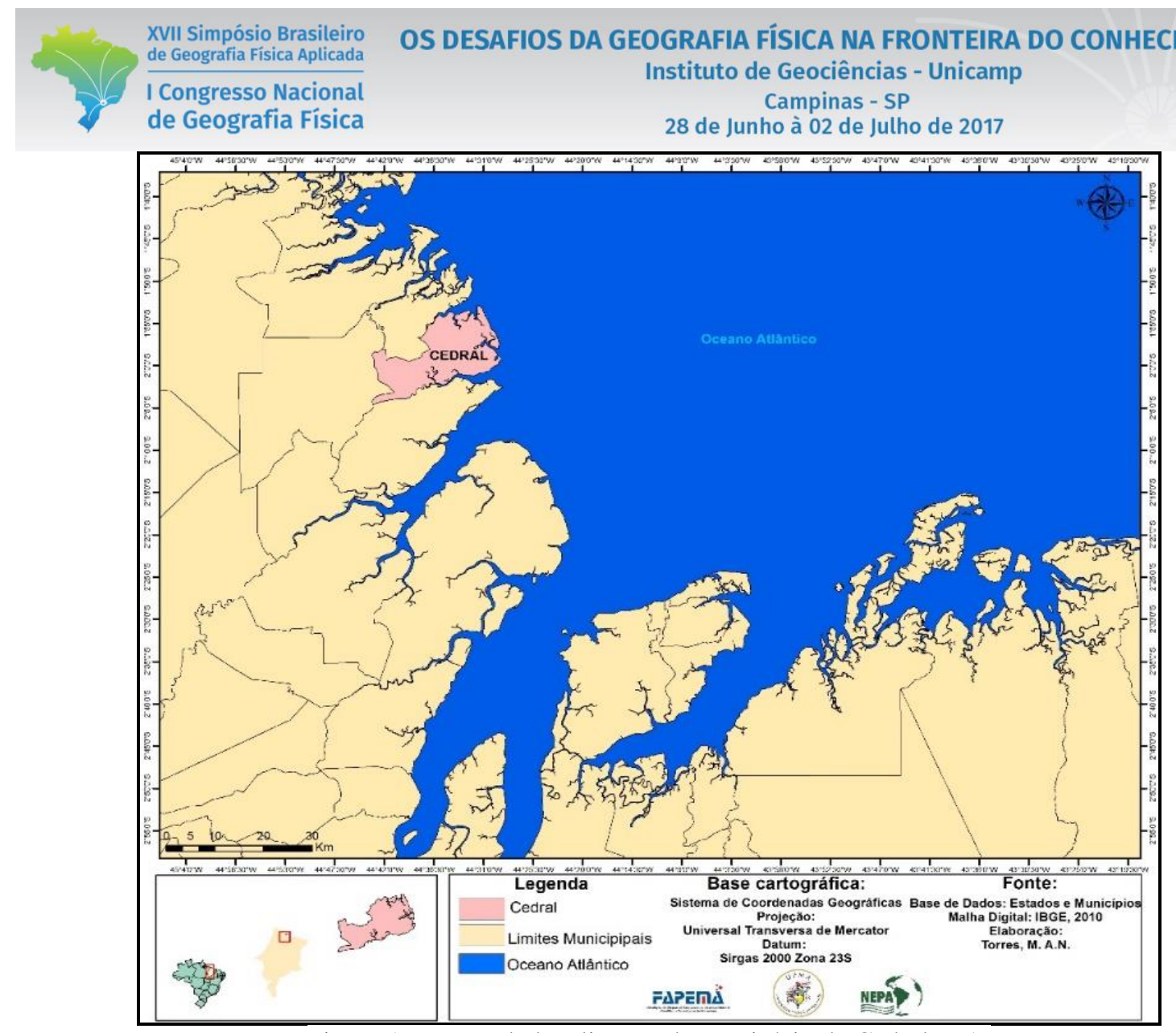

Figura 1 - Mapa de localização do município de Cedral-MA.

Compreendendo parte da APA das Reentrâncias, a zona costeira de Cedral possui domínio de formações geológicas do topo da bacia sedimentar de São Luís que, segundo Carvalho (2001), correspondem ao Cenozoico, sendo caracterizados por depósitos fluviais, representados por rochas conglomeradas de arenitos e argilitos e sedimentos do Quaternário, com predomínio de aluviões marinhos e fluviomarinhos.

A paisagem é marcada por ambientes estuarinos, referidos como desaguadouros de rios no oceano, oposto ao delta, que aparece geralmente constituído por vários braços (GUERRA e GUERRA, 2011). Nestas áreas ocorrem extensas áreas de manguezais e vegetação de restinga, ambientes que servem de refúgio para aves migratórias, extração de mariscos e crustáceos, além de extensa zona praial (Figura 2), definidas por Muehe (2012) como áreas de deposição de sedimentos, mais comumente arenosos, acumulados por ação de ondas que, por apresentar alta mobilidade, se ajustam às condições de ondas e maré atuando como um importante elemento de proteção do litoral. Na costa emersa ocorrem extensas faixas de Dunas e Paleodunas além de amplos tabuleiros costeiros. 


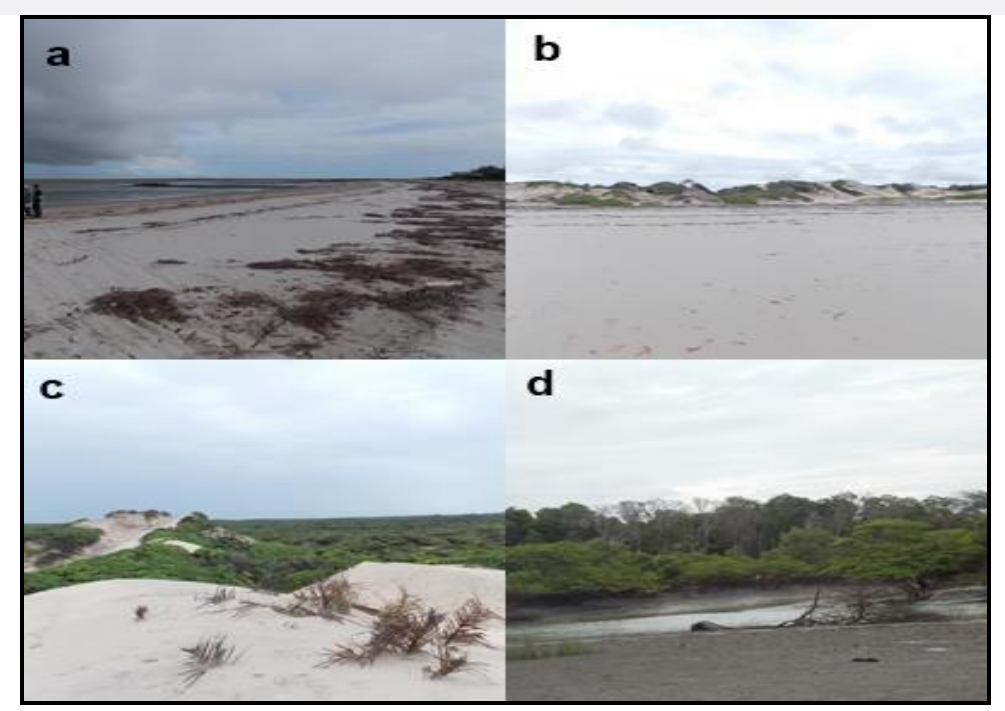

Figura 2 - a: Faixa de praia; b: Dunas rebaixadas; c: Vegetação de Restinga; d: Canal de maré.

\section{Resultados e Discussão}

Para se viabilizar uma proposta integrada de gestão do espaço costeiro, as iniciativas devem partir das diferentes esferas: federal, estadual e municipal, conforme pode ser observado no quadro 01 .

Quadro I - Atuação dos órgãos ambientais na área estudada

\begin{tabular}{|c|l|}
\hline ESCALA DE ATUAÇÃO & \multicolumn{1}{c|}{ PROPOSTAS DE GESTÃO } \\
\hline Federal & Fiscalização por parte do IBAMA \\
\hline Estadual & $\begin{array}{l}\text { Criação da APA das Reentrâncias Maranhenses; Fiscalização por parte da } \\
\text { Secretaria Estadual do Meio Ambiente. }\end{array}$ \\
\hline Municipal & Prefeitura Municipal Secretaria Municipal de Meio Ambiente \\
\hline
\end{tabular}

Fonte: IBAMA, SEMA, Prefeitura Municipal e Secretaria Municipal de Meio Ambiente de Cedral.

Quando a escala de atuação do IBAMA, órgão federal de atuação ambiental, a área não possui nenhum plano de gestão dos recursos costeiros, pois a gestão seria feita pelo Estado do Maranhão mais precisamente pela Secretária Estadual de Meio Ambiente - SEMA. Todavia, a mudança de escala governamental não alterou o quadro de gestão ambiental do município, pois a SEMA não faz nenhuma ação especifica na Unidade de Conservação, ficando evidente a ausência de ações de fiscalização ou gestão na área, sendo que, mesmo após mais de 20 anos da criação da APA, não existe nada de concreto quanto a elaboração do plano de manejo da área, contrariando ao que diz o Ministério do Meio Ambiente (2017), quando afirma que após a criação de uma UC, o plano de manejo deve ser elaborado em um prazo máximo de cinco anos. Toda UC deve ter um plano de manejo, que deve ser elaborado em função dos 


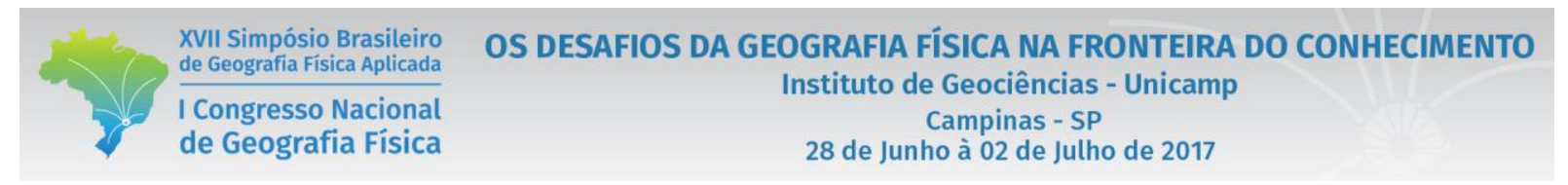

objetivos gerais pelos quais ela foi criada. Portanto, o estado e seus órgãos ambientais ficam limitados de fazer uma gestão adequado no na apa e, por conseguinte no território municipal de Cedral (este todo inserido dentro da APA das Reentrâncias Maranhenses), restringindo-se apenas as ações isoladas.

Quanto a gestão municipal, a partir de informações da prefeitura e dos representantes da secretaria de meio ambiente, constatou a falta de qualquer plano de fiscalização e gestão municipal da área costeira do seu território. A cidade ainda não é assistida de forma correta pois as gestões passadas e atual não criaram ao menos um plano de diretor que potencialize as atividades da cidade e fortaleça as ações ambientais da área. A secretaria de Meio ambiente por sua vez também não possui ações concretas efetivas

\section{Conclusão}

Constatou-se a notável importância ambiental do município, no entanto, este ainda é carente de leis e fiscalização efetiva que venham reger os recursos costeiros e as atividades praticadas nos limites da área. A falta de um plano de manejo, torna a fiscalização feita pelos órgãos ambientais isoladas, acontecendo apenas diante de denúncia ou períodos específicos. Portanto é imprescindível uma gestão e fiscalização ativas, cumprindo-se no mínimo o prescrito por lei, sendo o maior.

Portanto, a inexistência de articulação efetiva entre os órgãos federais, estaduais e municipais para a gestão de manejo integrada dos recursos da área costeira do município constitui um fator negativo para a preservação e conservação ambiental. Convém salientar que as ações isoladas e esporádicas destes órgãos inviabilizam o cumprimento da legislação ambiental.

\section{REFERÊNCIAS}

BRASIL, Instituto Brasileiro de Geografia e Estatística. Bases de Informações do Censo Demográfico 2010: Rio de Janeiro: IBGE, 2011.

BRASIL, Lei $\mathbf{n}^{\mathbf{0}} \mathbf{7 . 6 6 1}$, de 16 de maio de 1988, institui o Plano Nacional de Gerenciamento Costeiro e dá outras providências. Brasília, 16 de maio de 1988.

BRASIL, Ministério do Meio Ambiente. Plano Nacional de Gerenciamento Costeiro. Brasília: MMA, 2014.

CARVALHO, I. de S. A Bacia de São Luís. In: BRITO, I. M. Geologia histórica. Uberlândia: EDUFU, 2001.

GUERRA, A. J.; GUERRA, A. J. T. Novo dicionário geológico-geomorfológico. 9a ed. Rio de Janeiro: Bertrand Brasil, 2011.

KAPLAN, Abraham. A Conduta na pesquisa: metodologia para as ciências do comportamento. São Paulo: EPU, Ed. da Universidade de São Paulo, 1975. 


\begin{tabular}{|c|c|}
\hline $\begin{array}{l}\text { XVII Simpósio Brasileiro } \\
\text { de Geografia Fisica Aplicada } \\
\end{array}$ & $\begin{array}{l}\text { OS DESAFIOS DA GEOGRAFIA FÍSICA NA FRONTEIRA DO CONHECIMENTO } \\
\text { Instituto de Geociências - Unicamp }\end{array}$ \\
\hline $\begin{array}{l}\text { I Congresso Nacional } \\
\text { de Geografia Física }\end{array}$ & $\begin{array}{l}\text { Campinas - SP } \\
28 \text { de Junho à } 02 \text { de Julho de } 2017\end{array}$ \\
\hline
\end{tabular}

MARANHÃO. Decreto Estadual no. 11.901. Cria, no Estado do Maranhão, a Área de Proteção Ambiental das Reentrâncias Maranhenses, com limites que especifica e dá outras providências. São Luís, 11 de junho de 1991.

Ministério do Meio Ambiente. Plano de Manejo. Disponível em:<http://www.mma.gov.br/areasprotegidas/unidades-de-conservacao/plano-de-manejo>. Acesso em 12 de abril de 2017.

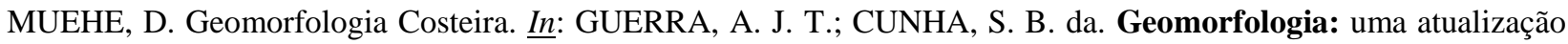
de bases e conceitos. - $11^{\mathrm{a}}$ ed. - Rio de Janeiro: Betrand Brasil, 2012. 